\title{
Microstructure Evolution of Carbon Fiber in PIP-processed C/SiC Composites under High Temperature Environment
}

\author{
Xiang Yang, Wang Qing, Cai Hua-fei, Liu Ying, Cao Feng \\ Science and Technology on Advanced Ceramic Fibers and Composites Laboratory \\ National University of Defense Technology, Changsha P. R China \\ e-mail: shmily_0427@163.com
}

\begin{abstract}
The thermal stability of carbon fiber in PIPprocessed $\mathrm{C} / \mathrm{SiC}$ composites under high temperature environment was studied. The microstructure evolution of carbon fiber in PIP-C/SiC composites was characterized. The results showed that the microstructure of carbon fiber gradually destroyed with the elevation of annealing temperature. When the annealing temperature reached $1800^{\circ} \mathrm{C}$, the integrity of carbon fiber was destroyed, which corresponding to the descend of mechanical properties. Further study on the mechanisms of carbon fiber is needed and is in progress.
\end{abstract}

Keywords-C/SiC composites; PIP; carbon fiber; high temperature

\section{INTRODUCTION}

The incorporation of continuous carbon fibers into ceramics offered a promising route to the production of tough and reliable ceramic materials [1]. Due to their low specific weight, high strength, excellent resistance to ablation as well as cost effective production, carbon fiber reinforced silicon carbide $(\mathrm{C} / \mathrm{SiC})$ composites represented an interesting material for high-temperature structural applications [2-4].

The most common techniques for producing $\mathrm{C} / \mathrm{SiC}$ composites were Chemical Vapor Infiltration (CVI), Liquid Silicon Infiltration (LSI) and Polymer Infiltration and Pyrolysis (PIP), or a combination of the above. PIP process was conversely much cost and time effective [5-10].

In PIP process, a critical issue for utilization of carbon fibers was their thermal stability. The carbon fibers were vulnerable to severe property degradation due to decomposition, oxidation, accelerated grain growth, or a combination of the above during high-temperature processing and service environment [11].

The purpose of the present paper was to evaluate the microstructure evolution of carbon fiber in PIP-processed $\mathrm{C} / \mathrm{SiC}$ composites under high temperature environment is discussed.

\section{EXPERIMENTAL Procedings}

\section{A. Morphology Preparation of PIP-C/SiC composites}

Polycarbosilane (PCS) (molecular weight: 1742, soften point: $175^{\circ} \mathrm{C}$ ) was synthesized in our laboratory. Xylene was used as the solvent for PCS.

Three-dimensional braided carbon fibers (T-300, ex-PAN carbon fibers, Toray) were used as the reinforcement, and the fibers volume fraction was $45 \%$. 9 12 cycles of infiltration of PCS-Xylene solution (mass ratio1: 1) and subsequently pyrolyzed at $1200^{\circ} \mathrm{C}$ under $\mathrm{N}_{2}$ (purity: 99.99\%) atmosphere [3].

B. High-temperature annealing experiment and Samples characterization

High temperature annealing processes were carried out by annealing between $1400^{\circ} \mathrm{C}$ and $2000^{\circ} \mathrm{C}$ for $1 \mathrm{~h}$ under $\mathrm{Ar}$ atmosphere.

The microstructures of the samples after hightemperature annealing experiment were examined by scanning electron microscopy (SEM, FEI Quanta-200).

\section{Results AND Discussion}

\section{A. Morphology of carbon fiber in PIP-processed C/SiC composites}

The typical morphology of the carbon fiber is shown in Figure 1. The fiber is near rotundity in shape and the diameter is about $7 \mu \mathrm{m}$.

The surface of the fiber is rough. It can be seen that there are visible cracks on the surface, which are caused by PIP process. PCS shrinks in pyrolysis, and then $\mathrm{O}$ element in the PCS is reacted with carbon fiber, which may result cracks on the surface of the fibers. 

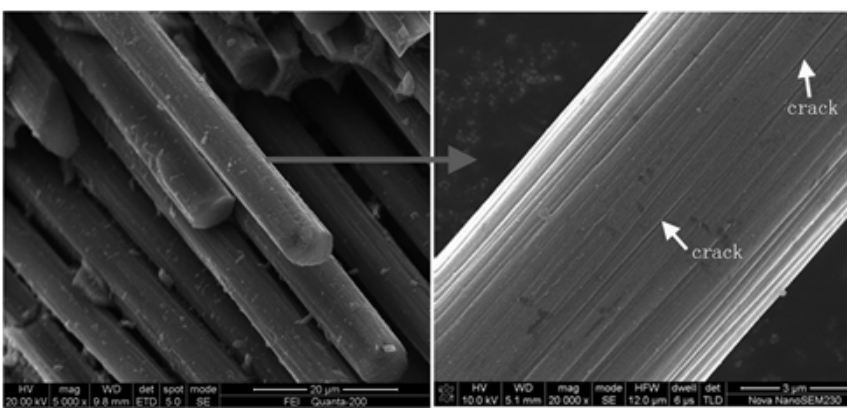

Figure 1. Surface morphology of as-fabricated carbon fibers

It was well known that the interfacial bonding strength had a great effect on the mechanical properties of $\mathrm{C} / \mathrm{SiC}$ composites [12]. When the fibers were coated by $\mathrm{SiC}$ matrix, it reinforces the interfacial bonding and improved the accommodation of the fiber/matrix. As a result, the composites exhibited higher flexural strength and an evident toughened fracture behavior [4].

\section{B. Microstructure evolution of carbon fiber in PIP- processed C/SiC composites}

The microstructure of carbon fiber in PIP-processed $\mathrm{C} / \mathrm{SiC}$ composites under high temperature environment is shown in Figure 2-Figure 5. The changes of carbon fiber after high temperature annealing processes are verified by the SEM.

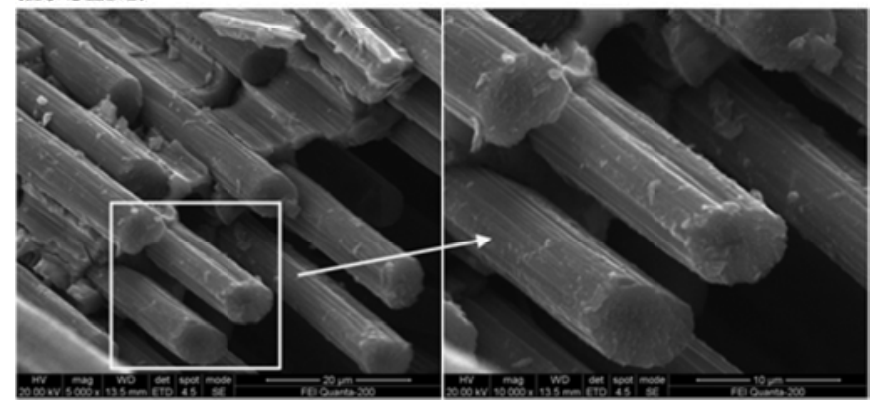

Figure 2. Surface morphology of carbon fibers under $1400^{\circ} \mathrm{C}$ annealing

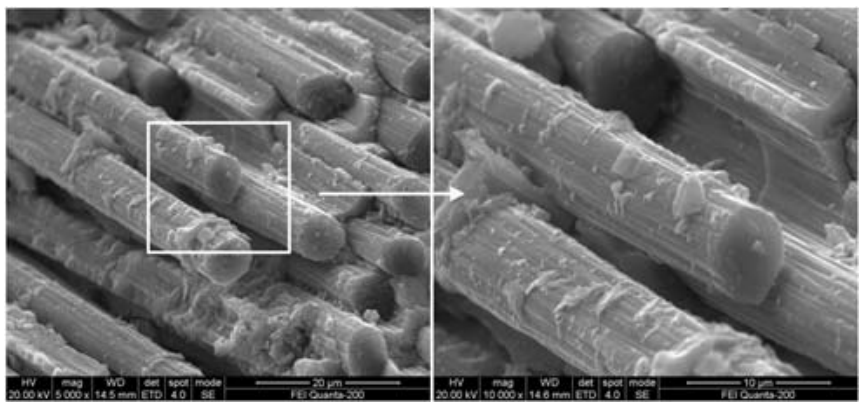

Figure 3. Surface morphology of carbon fibers under $1600^{\circ} \mathrm{C}$ annealing

Compared with the similarly visible difference in surface morphology under different temperature, there is distinct surface morphologic change between the samples shown in Figure 2-Figure 5. Together with above-mentioned features, a very interesting phenomenon is also observed. The reasons of mechanical behavior of PIP-processed $\mathrm{C} / \mathrm{SiC}$ composites
[13] can be understood from inspection of SEM images (Figure 2-Figure 5).

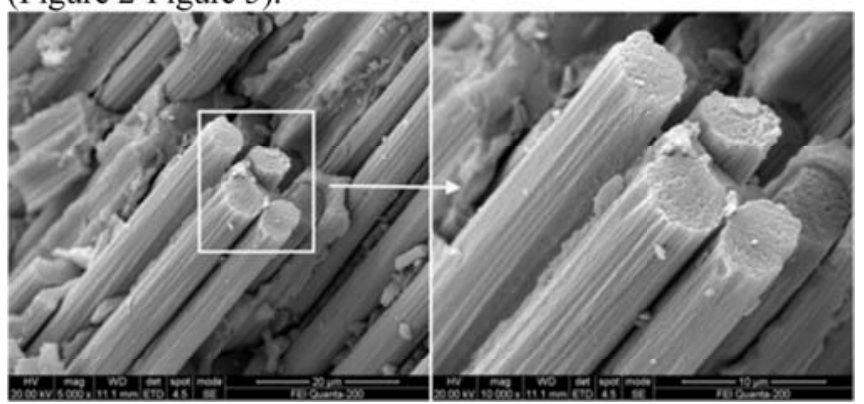

Figure 4. Surface morphology of carbon fibers under $1800^{\circ} \mathrm{C}$ annealing

The SEM images of carbon fibers after treatment at $1400^{\circ} \mathrm{C}$ are presented in Figure 2. One can observe large cracks in the fibers.

The formation of large size cracks can be connected with coalescence of small size cracks and diffusion of them outward. The version on the formation of cracks due to the interaction of carbon fibers and PCS is unlikely because of high-temperature in the process. One can also propose that cracks could originate from gas evolution (e.g. hydrogen) from carbon fibers themselves during the high-temperature treatment.

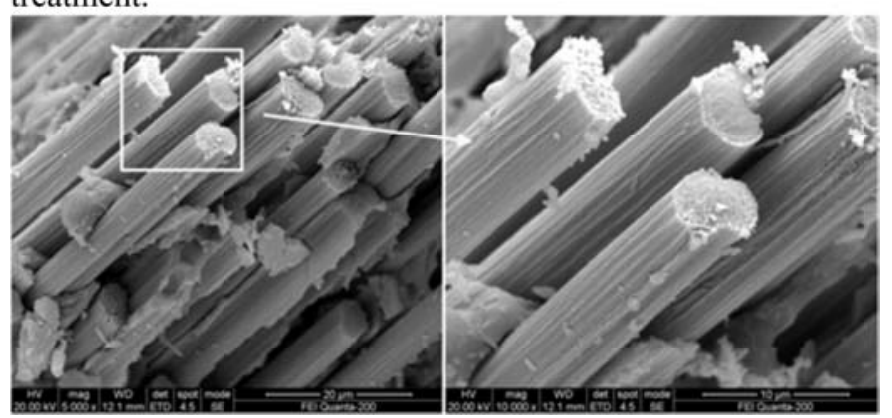

Figure 5. Surface morphology of carbon fibers under $2000^{\circ} \mathrm{C}$ annealing

The SEM images of carbon fibers after treatment at $1600^{\circ} \mathrm{C}$ are presented in Figure 3. For the fracture of carbon fibers, the $\mathrm{CF}$ is not clean and the matrix is not comparatively neat, which indicated a strong interface. With the treatment, the matrix became rougher and more $\mathrm{SiC}$ matrix attached to CF. An amount of resin adhering to the carbon fiber surface could be seen (marked in circles), which is an evidence of a stronger interphase. At the fiber surface with many large catalyst particles (bright contrast in the SEM image) the pitting is significantly deeper and densely distributed. This observation indicates that excessive etching of the carbon fiber surface occurred at large catalyst particles, as will be explained later in the text.

One can see that with increasing temperature to $1800^{\circ} \mathrm{C}$, the morphology of the carbon fibers is drastically changed (Figure 4). Due to an agglomeration and recrystallization of carbon particles, the smooth areas are observed, whereas the other areas become loose.

The carbon fibers cannot retain their morphology after high-temperature treatment, which corresponding the decline 
of mechanical behavior of PIP-processed $\mathrm{C} / \mathrm{SiC}$ composites [13].

The carbon fibers under $2000^{\circ} \mathrm{C}$ annealing are thinner compared with the others (Figure 5), the microstructure of the carbon fibers sharply changes. The integrity of carbon fiber is destroyed, which homologous to the tragedy of mechanical properties [13].

Therefore, the microstructure of carbon fibers sharply changes after high-temperature heat treatment.

Further study on the mechanisms of carbon fiber is needed and is in progress.

\section{CONCLUSIONS}

The thermal stability of carbon fiber in PIP-processed $\mathrm{C} / \mathrm{SiC}$ composites under high temperature environment was studied:

- The microstructure of carbon fiber gradually destroyed with the elevation of annealing temperature.

- When the annealing temperature reached $1800^{\circ} \mathrm{C}$, the integrity of carbon fiber was destroyed, which corresponding to the descend of mechanical properties.

- Further study on the mechanisms of carbon fiber is needed and is in progress.

\section{ACKNOWLEDGEMENTS}

The authors are grateful to National Science Foundation of China (51402357) for financial support. The authors are also grateful to Aid Program for Innovative Group of National University of Defense Technology and Aid Program for Science and Technology Innovative Research Team in Higher Educational Institutions of Hunan Province.

\section{REFERENCES}

[1] W. Lin, and J. M. Yang. "Thermal stability of ceramic fibre in a CVIprocessed $\mathrm{SiC}$ matrix composite," Journal of material science, 26 (1991) 4116-4122.

[2] G. D. Li, Y. D. Zhang, C. R. Zhang, et al., "Design, preparation and properties of online-joints of $\mathrm{C} / \mathrm{SiC}-\mathrm{C} / \mathrm{SiC}$ with pins," Composites Part B: Engineering 48 (2013) 134-139.

[3] K. Jian, Z.H. Chen, Q.S. Ma, et al., "Effects of polycarbosilane infiltration processes on the microstructures and mechanical properties of $3 \mathrm{D}-\mathrm{Cf} / \mathrm{SiC}$ composites," Ceramics International 33 (2007) 905-909.

[4] X. Yang, L. Wei, W. Song, et al., "Oxidation behavior of oxidation protective coatings for $\mathrm{PIP}-\mathrm{C} / \mathrm{SiC}$ composites at $1500^{\circ} \mathrm{C}$," Ceramics International 38 (2012) 9-13.

[5] M. Pavese, P. Fino, C. Badini, et al., "HfB2/SiC as a protective coating for $2 \mathrm{D} \mathrm{Cf} / \mathrm{SiC}$ composites: Effect of high temperature oxidation on mechanical properties," Surface \& Coatings Technology 202 (2008) 2059-2067.

[6] L. Wei, X. Yang, W. Song, et al., "Ablation behavior of threedimensional braided $\mathrm{C} / \mathrm{SiC}$ composites by oxyacetylene torch under different environment," Ceramics International 39 (2013) 463-468.

[7] X. Yang, L. Wei, W. Song, et al., "Microstructures and mechanical properties of CVD-SiC coated PIP-C/SiC composites under high temperature," Surface \& Coatings Technology 209 (2012) 197-202.

[8] H. Mei, L. Cheng, L. Zhang, X. Luan, and J. Zhang, "Behavior of two dimensional $\mathrm{C} / \mathrm{SiC}$ composites subjected to thermal cycling in controlled environments," Carbon 44 (2006) 121-127.

[9] Y. J. Lee, and H.J. Joo, "Investigation on ablation behavior of CFRC composites prepared at different pressure," Composites Part A: Applied Science and Manufacturing 35 (2004) 1285-1290.

[10] S. Zhao, X.G. Zhou, H.J. Yu, H.L. Wang, et al., "Compatibility of PIP $\mathrm{SiCf} / \mathrm{SiC}$ with $\mathrm{LiPb}$ at $7008 \mathrm{C}$," Fusion Eng. Des. 85 (2010) 16241626.

[11] K. Jian, Z.H. Chen, Q.S. Ma, et al., "Effects of pyrolysis processes on the microstructures and mechanical properties of $\mathrm{Cf} / \mathrm{SiC}$ composites using polycarbosilane," Mater. Sci. Eng. A 390 (2005) 154-158.

[12] K. Jian, Z.H. Chen, Q.S. Ma, et al., "Effects of pyrolysis processes on the microstructures and mechanical properties of $\mathrm{Cf} / \mathrm{SiC}$ composites using polycarbosilane," Mater. Sci. Eng. A 390 (2005) 154-158.

[13] M. Yan, S. Wang, and Z.H. Chen. "Effects of high-temperature annealing on the microstructures and mechanical properties of $\mathrm{Cf} / \mathrm{SiC}$ composites using polycarbosilane," Materials Science and Engineering A 528 (2011) 3069-3072. 